\title{
Solubility of Anthracene in Ternary Dibutyl Ether + Alcohol + Cyclohexane Solvent Mixtures
}

\author{
Karen J . Pribyla and William E. Acree, J r.* \\ Department of Chemistry, University of North Texas, Denton, Texas 76203-5070
}

\begin{abstract}
Experimental solubilities are reported for anthracene dissolved in ternary dibutyl ether +1 -propanol + cyclohexane, dibutyl ether + 2-propanol + cycl ohexane, dibutyl ether + 1-butanol + cyclohexane, dibutyl ether + 2-butanol + cyclohexane, and dibutyl ether +2 -methyl-1-propanol + cyclohexane solvent mixtures at $25^{\circ} \mathrm{C}$ and atmospheric pressure. Nineteen compositions were studied for each of the five solvent systems. Results of these measurements are used to test the predictive ability of the ternary solvent form of the combined NIMS/Redlich-Kister equation. Computations showed that the model predicted the observed solubility behavior to within an overall average absolute deviation of about $1.5 \%$, which is comparable to the experimental uncertainty of $\pm 1.5 \%$.
\end{abstract}

\section{Introduction}

Solid-liquid equilibrium data of organic nonelectrolyte systems are becoming increasingly important in the pe troleum industry, particularly in light of present trends toward heavier feedstocks and the known carcinogenicity/ mutagenicity of many of the larger polycyclic aromatic compounds. Solubility data for a number of polycyclic aromatic hydrocarbons (i.e., anthracene and pyrene) and heteroatom polynuclear aromatics (i.e., carbazole, dibenzothiophene, and xanthene) have been published in the recent chemical literature. For a listing of references, see Acree (1994, 1995a,b). Despite efforts by experimentalists and scientific organizations, both in terms of new experimental measurements and critically evaluated data compilations, there still exist numerous systems for which solubility data are not readily available.

To address this problem, researchers have turned to group contribution methods and semiempirical equations to predict desired quantities from either pure component properties or measured binary data. In earlier studies we have used the binary solvent reduction of a predictive expression derived from a combined two- and three-body interactional mixing model as a mathematical representation for describing how the measured isothermal solubility of a crystalline solute varies with binary solvent composition. The binary reduction, referred to as the combined NIBS/Redlich-Kister equation, was found to accurately describe the observed solubility behavior in a large number of different binary solvent systems. We recently extended our solubility studies to ternary two alkane + alcohol (Deng and Acree, 1998a; Deng et al., 1999a) and alkane + two alcohol (Deng and Acree, 1998b; Deng et al., 1998 and 1999b) solvent mixtures. Such systems exhibit hydrogenbond formation, and the measured solubility data will be used in future studies to test expressions derived from both the Kretschmer-Wiebe association model and Mobile Order theory. Deviations from ideality arise from the selfassociation of each alcohol cosolvent and, in mixtures containing two alcohol cosolvents, from the formation of

* To whom correspondence should be addressed. E-mail: acree@ unt.edu. Fax: (940) 565-4318. heterogeneous hydrogen-bonded chains between dissimilar alcohol molecules. Powell et al. (1997b) and McHale et al. (1996) showed that the aforementioned thermodynamic models provided reasonably accurate descriptions for the solubility behavior of pyrene and anthracene in binary alkane + alcohol and alcohol + alcohol solvent mixtures.

In the present study anthracene solubilities have been measured in the five ternary dibutyl ether + alcohol + cyclohexane systems at $25^{\circ} \mathrm{C}$. Nineteen ternary compositions were studied for each of the five systems. Unlike the ternary solvent mixtures studied previously, hydrogenbond formation is terminated each time that an alcohol molecule hydrogen bonds with dibutyl ether. Results of these measurements are used to test the predictive ability of expressions based upon the general mixing model used in deriving the combined NIBS/Redlich-Kister equation.

\section{Experimental Methods}

Anthracene (Acros, 99.9+\%) was recrystallized three times from 2-propanone. 1-Propanol (Aldrich, 99+\%, anhydrous), 2-propanol (Aldrich, 99+\%, anhydrous), 1-butanol (Aldrich, HPLC, 99.8+\%), 2-butanol (Aldrich, 99+\%, anhydrous), 2-methyl-1-propanol (Aldrich, 99.5\%, anhydrous), cyclohexane (Aldrich, HPLC, 99.9+\%), and dibutyl ether (Aldrich, 99.3\%, anhydrous) were stored over molecular sieves and distilled shortly before use. Gas chromatographic analysis showed solvent purities to be $99.7 \mathrm{~mol} \%$ or better. Ternary solvent mixtures were prepared by mass so that compositions could be calculated to 0.0001 mole fraction. The methods of sample equilibration and spectrophotometric analysis are discussed in an earlier paper (Powell et al., 1997a). Experimental anthracene solubilities in the five dibutyl ether + alcohol + cyclohexane solvent mixtures are listed in Table 1. Numerical values represent the average of between four and eight independent determinations, with the measured values being reproducible to within $\pm 1.5 \%$.

\section{Results and Discussion}

Expressions for predicting the thermodynamic properties of ternary nonelectrolyte systems have served as the point 
J ournal of Chemical and Engineering Data, Vol. 44, No. 5, 19991021

of departure for mathematical representation of experimental excess molar Gibbs energy, excess molar heat capacity, excess molar enthal py, and excess molar volume data. Differences between predicted and observed values are expressed as

$$
\left(Z_{A B C}^{E}\right)^{\text {exp }}-\left(Z_{A B C}^{E}\right)^{\text {calc }}=x_{A} x_{B} x_{C} Q_{A B C}
$$

with Q functions of varying complexity. For most systems encountered, the experimental data can be adequately represented by a power series expansion

$$
\begin{array}{r}
Q_{A B C}=A_{A B C}+\sum_{i=1}^{r} B_{A B}^{(i)}\left(x_{A}-x_{B}\right)^{i}+ \\
\sum_{j=1}^{s} B_{A C}(j)\left(x_{A}-x_{C}\right)^{j}+ \\
\sum_{k=1}^{t} B_{B C}(k)\left(x_{B}-x_{C}\right)^{k}(2)
\end{array}
$$

though rarely are experimental data determined with sufficient precision to justify more than a few parameters.

Conceptually, these ideas can be extended to solute solubilities in binary solvent mixtures. However, there has never been up until recently a sufficiently large solid solute solubility database to warrant computerized storage in equational form. With computerized data storage and retrieval becoming increasingly popular, it seems appropriate to discuss the various mathematical expressions that have been proposed in the chemical literature for describing the variation of solute solubility with binary solvent composition. Mathematical representations not only provide a means to screen experimental data sets for possible outliers in need of redetermination but also facilitate interpolation at solvent compositions falling between measured data points.

Acree and co-workers (Acree, 1992; Acree and Zvaigzne, 1991; Acree et al., 1991) suggested a possi ble mathematical representation for isothermal solubility data based upon the combined NIBS/Redlich-Kister model

$$
\ln x_{A}^{\text {sat }}=x_{B}^{\circ} \ln \left(x_{A}^{\text {sat }}\right)_{B}+x_{C}^{\circ} \ln \left(x_{A}^{\text {sat }}\right)_{C}+x_{B}^{\circ} x_{C}^{\circ} \sum_{i=0}^{n} S_{i}\left(x_{B}^{\circ}-x_{C}^{\circ}\right)^{i}
$$

where $x_{B}^{\circ}$ and $x_{C}^{\circ}$ refer to the initial mole fraction composition of the binary solvent calculated as if the solute were not present and $\left(x_{A}^{\text {sat }}\right)_{i}$ denotes the measured solute solubility in pure solvent $i$. The various $S_{i}$ curve-fit parameters can be evaluated with a least-squares analysis. Published papers (Zvaigzne et al., 1993 and 1994; Zvaigzne and Acree, 1994; Powell and Acree, 1995; Acree et al., 1994) have reported the calculated $S_{i}$ parameters for anthracene dissolved in 10 of the 11 subbinary solvent systems, as well as the measured mole fraction solubilities in 1-propanol $\left(x_{A}^{\text {sat }}=0.000591\right), 2$-propanol $\left(x_{A}^{\text {sat }}=0.000411\right)$, 1-butanol $\left(x_{A}^{\text {sat }}=0.000801\right), 2$-butanol $\left(x_{A}^{\text {sat }}=0.000585\right), 2$-methyl1-propanol $\left(x_{A}^{\text {sat }}=0.000470\right)$, cyclohexane $\left(x_{A}^{\text {sat }}=\right.$ $0.001553)$, and dibutyl ether $\left(x_{A}^{\text {sat }}=0.003615\right)$. Solubility data for the el eventh binary solvent system were reported several years prior to the development of the combined NIBS/Redlich-Kister equation. We have determined the numerical values of the $S_{i}$ parameters for the binary dibutyl ether + cydlohexane solvent system by curve fitting the experimental anthracene mole fraction solubility data of Marthandan and Acree (1987) in accordance with eq 3. Numerical values of the $S_{i}$ parameters have been tabulated in Table 2 for convenience.

\begin{tabular}{|c|c|c|c|c|c|}
\hline$x_{B}^{\circ}$ & $x_{c}^{\circ}$ & $x_{A}^{\text {sat }}$ & $x_{B}^{\circ}$ & $x_{c}^{0}$ & $x_{A}^{\text {sat }}$ \\
\hline \multicolumn{6}{|c|}{ Dibutyl Ether (B) + 1-Propanol (C) + Cyclohexane (D) } \\
\hline 0.2048 & 0.4725 & 0.001883 & 0.1013 & 0.2196 & 0.001817 \\
\hline 0.0829 & 0.7919 & 0.001078 & 0.5267 & 0.2862 & 0.002812 \\
\hline 0.1571 & 0.3599 & 0.001868 & 0.3307 & 0.4042 & 0.002260 \\
\hline 0.1444 & 0.6322 & 0.001477 & 0.0673 & 0.2755 & 0.001700 \\
\hline 0.5557 & 0.1911 & 0.002866 & 0.0581 & 0.7822 & 0.001021 \\
\hline 0.5146 & 0.3534 & 0.002707 & 0.1353 & 0.1581 & 0.001946 \\
\hline 0.1064 & 0.8015 & 0.001114 & 0.0636 & 0.5051 & 0.001432 \\
\hline 0.0611 & 0.6006 & 0.001285 & 0.2819 & 0.1716 & 0.002258 \\
\hline 0.2761 & 0.6272 & 0.001783 & 0.3502 & 0.1940 & 0.002409 \\
\hline 0.3104 & 0.5792 & 0.002007 & & & \\
\hline \multicolumn{6}{|c|}{ Dibutyl Ether (B) + 2-Propanol (C) + Cyclohexane (D) } \\
\hline 0.2085 & 0.4629 & 0.001764 & 0.0876 & 0.2459 & 0.001783 \\
\hline 0.0804 & 0.7946 & 0.000901 & 0.5322 & 0.2793 & 0.002725 \\
\hline 0.1595 & 0.3583 & 0.001829 & 0.3408 & 0.3834 & 0.002166 \\
\hline 0.1423 & 0.6291 & 0.001337 & 0.0659 & 0.2768 & 0.001631 \\
\hline 0.5532 & 0.1930 & 0.002866 & 0.0581 & 0.7789 & 0.000876 \\
\hline 0.5205 & 0.3386 & 0.002609 & 0.1342 & 0.1578 & 0.001903 \\
\hline 0.1095 & 0.8006 & 0.000943 & 0.0649 & 0.5031 & 0.001330 \\
\hline 0.0624 & 0.5968 & 0.001176 & 0.2799 & 0.1784 & 0.002287 \\
\hline 0.2398 & 0.6594 & 0.001487 & 0.3611 & 0.1831 & 0.002434 \\
\hline 0.3150 & 0.5723 & 0.001816 & & & \\
\hline \multicolumn{6}{|c|}{ Dibutyl Ether (B) + 1-Butanol (C) + Cyclohexane (D) } \\
\hline 2276 & 0.4225 & 0.002015 & 0.1032 & 0.1886 & 0.001889 \\
\hline 0.0932 & 0.7567 & 0.001310 & 0.5607 & 0.2398 & 0.002908 \\
\hline 0.1718 & 0.3132 & & 0.3549 & 0.3531 & 0.002347 \\
\hline 0.1623 & 0.5790 & 718 & 0.0699 & 0.2412 & 0.001794 \\
\hline & 0.1685 & & 0.0642 & 0.7467 & \\
\hline 0.5536 & 0.3029 & 0.002840 & 0.1354 & 0.1357 & 0.001999 \\
\hline 0.1237 & 0.7723 & 1370 & 0.0721 & 0.4500 & 0.001604 \\
\hline 0.0683 & 0.5553 & 001499 & 0.2926 & 0.1472 & 0.002290 \\
\hline & 0.6125 & & 0.3690 & 0.1587 & 0.002408 \\
\hline 0.3477 & 0.5235 & 0.002233 & & & \\
\hline \multicolumn{6}{|c|}{ Dibutyl Ether (B) + 2-Butanol (C) + Cyclohexane (D) } \\
\hline .2263 & 0.4202 & 0.001953 & 0.1068 & 0.1852 & 0.001888 \\
\hline .0883 & 0.7556 & 01118 & 0.5520 & 0.23 & 0.002876 \\
\hline 0.1620 & 0.3218 & & 0.35 & 0.35 & 0.002334 \\
\hline 0.1639 & 0.5791 & & 0.0688 & 0.2384 & 0.001750 \\
\hline 0.5718 & 0.1685 & & 0.06 & 0.74 & 0.001074 \\
\hline 0.5549 & 0.3047 & 0.002764 & 0.1353 & 0.1363 & 0.001971 \\
\hline 0.1227 & 0.7703 & 0.001184 & 0.0646 & 0.4555 & 0.001513 \\
\hline 0.0692 & 0.5495 & & 0.2894 & 0.1478 & 0.002339 \\
\hline 0.2677 & 0.6133 & 0.001779 & 0.3818 & 0.1541 & 0.002541 \\
\hline 0.3530 & 0.5220 & 0.002112 & & & \\
\hline \multicolumn{6}{|c|}{ Dibutyl Ether (B) } \\
\hline & & & 0.1058 & 0.1875 & 0.0 \\
\hline & & & & & 0.002810 \\
\hline 0.1766 & & & 0.3639 & 0.3433 & 0.002222 \\
\hline 0.1634 & 0.5744 & & 0.07 & 0.2402 & 0.001653 \\
\hline 0.5694 & 0.1686 & & 0.06 & 0.7413 & 0.000939 \\
\hline 0.55 & 0.3059 & & 0.1 & 0.13 & 0.001941 \\
\hline 0.12 & 0.7694 & 0.001032 & 0.0703 & 0.4527 & 0.001375 \\
\hline & 0.5503 & 0.001229 & 0.2902 & 0.1523 & \\
\hline 0.2681 & 0.6128 & 0.001594 & 0.3756 & 0.1556 & 0.002402 \\
\hline & & 0.001946 & & & \\
\hline
\end{tabular}

Table 1. Experimental Mole Fraction Solubilities of Anthracene $\left(x_{A}^{\text {sat }}\right)$ in Ternary Dibutyl Ether $(B)+$ Alcohol (C) + Cyclohexane (D) Solvent Mixtures at $298.15 \mathrm{~K}$

Equation 3 expresses the excess logarithmic mole fraction solubility, relative to the simple $x_{B}^{\circ} \ln \left(x_{A}^{\text {sat }}\right)_{B}+$ $x_{C}^{\circ} \ln \left(x_{A}^{\text {sat }}\right)_{C}$ arithmetic average, in terms of the RedlichKister equation. For a ternary solvent system, the mathematical representation takes the form

$$
\begin{array}{r}
\ln x_{A}^{\text {sat }}=x_{B}^{\circ} \ln \left(x_{A}^{\text {sat }}\right)_{B}+x_{C}^{\circ} \ln \left(x_{A}^{\text {sat }}\right)_{C}+x_{D}^{\circ} \ln \left(x_{A}^{\text {sat }}\right)_{D}+ \\
x_{B}^{\circ} x_{C}^{\circ} \sum_{i=0}^{r} S_{i, B C}\left(x_{B}^{\circ}-x_{C}^{\circ}\right)^{i}+x_{B}^{\circ} x_{D}^{\circ} \sum_{i=1}^{n} S_{j, B D}\left(x_{B}^{\circ}-x_{D}^{\circ}\right)^{j}+ \\
x_{C}^{\circ} x_{D}^{\circ} \sum_{k=1}^{t} S_{k, C D}\left(x_{C}^{\circ}-x_{D}^{\circ}\right)^{k}
\end{array}
$$


1022 J ournal of Chemical and Engineering Data, Vol. 44, No. 5, 1999

Table 2. Combined NIBS/Redlich-Kister Parameters (Eq 3) Calculated from Anthracene Solubilities in the Subbinary Solvent Systems

\begin{tabular}{|c|c|c|c|}
\hline solvent $B+$ solvent $C$ & $\mathrm{~S}_{\mathrm{i}}{ }^{\mathrm{a}}$ & solvent $\mathrm{B}+$ solvent $\mathrm{C}$ & $\mathrm{Si}^{\mathrm{a}}$ \\
\hline 2-methyl-1-propanol (B) + cyclohexane (C) & $\begin{array}{r}1.116 \\
-0.172 \\
0.341\end{array}$ & dibutyl ether $(B)+$ 2-propanol $(C)$ & $\begin{array}{r}2.588 \\
-1.235 \\
0.866\end{array}$ \\
\hline 2-propanol (B) + cyclohexane (C) & $\begin{array}{l}1.589 \\
0.143 \\
0.248\end{array}$ & dibutyl ether $(B)+$ 1-butanol (C) & $\begin{array}{r}1.736 \\
-0.488 \\
0.574\end{array}$ \\
\hline 2-butanol (B) + cyclohexane (C) & $\begin{array}{r}1.260 \\
-0.206\end{array}$ & dibutyl ether $(B)+$ 2-butanol (C) & $\begin{array}{r}2.109 \\
-0.849\end{array}$ \\
\hline 1-propanol (B) + cyclohexane (C) & $\begin{array}{r}1.121 \\
-0.040 \\
0.256\end{array}$ & dibutyl ether (B) + 2-methyl-1-propanol (C) & $\begin{array}{r}0.726 \\
2.231 \\
-0.932\end{array}$ \\
\hline 1-butanol (B) + cyclohexane (C) & $\begin{array}{r}0.741 \\
-0.345 \\
0.223\end{array}$ & dibutyl ether (B) + cyclohexane (C) & $\begin{array}{r}0.927 \\
0.467 \\
-0.190\end{array}$ \\
\hline dibutyl ether $(B)+$ 1-propanol $(C)$ & $\begin{array}{r}2.167 \\
-0.931 \\
0.891\end{array}$ & & \\
\hline
\end{tabular}

a Combined NIBS/Redlich-Kister curve-fit parameters are ordered as $\mathrm{S}_{0}, \mathrm{~S}_{1}$, and $\mathrm{S}_{2}$

Table 3. Summarized Comparison between Observed Anthracene Solubilities in Ternary Dibutyl Ether + Alcohol + Cyclohexane Solvent Mixtures and Predicted Values Based upon the Combined NIMS/Redlich-Kister eq 4

\begin{tabular}{cc}
\hline \multicolumn{1}{c}{ ternary solvent mixture } & $\%$ dev $^{\mathrm{a}}$ \\
\hline $\begin{array}{c}\text { dibutyl ether (B) + 1-propanol (C) + } \\
\text { cyclohexane (D) }\end{array}$ & 1.68 \\
$\begin{array}{c}\text { dibutyl ether (B) + 2-propanol (C) + } \\
\text { cyclohexane (D) }\end{array}$ & 1.16 \\
$\begin{array}{c}\text { dibutyl ether (B) + 1-butanol (C) + } \\
\text { cyclohexane (D) }\end{array}$ & 1.94 \\
$\begin{array}{c}\text { dibutyl ether (B) + 2-butanol (C) + } \\
\text { cyclohexane (D) }\end{array}$ & 1.07 \\
$\begin{array}{c}\text { dibutyl ether (B) + 2-methyl-1-propanol (C) + } \\
\text { cyclohexane (D) }\end{array}$ & 1.77 \\
\end{tabular}

a Deviation $(\%)=(100 / \mathrm{N}) \sum \mid\left[\left(x_{A}^{\text {sat }}\right)\right.$ calc $\left.-\left(x_{A}^{\text {sat }}\right)^{\exp }\right] /\left(x_{A}^{\text {sat }}\right) \exp \mid$, where $\mathrm{N}$ corresponds to the number of data points for each ternary system. In the present study, solubilities were determined at 19 different ternary solvent compositions.

In keeping with our established terminology, the generalized mathematical representation given below

$$
\ln x_{A}^{\text {sat }}=\sum_{1}^{\text {solv }} x_{1}^{\circ} \ln \left(x_{A}^{\text {sat }}\right)_{1}+\sum_{1}^{\text {solvsolv }} \sum_{J}\left[x_{1}^{\circ} x_{j}^{\circ} \sum_{k=0}^{n} S_{k, I j}\left(x_{l}^{\circ}-x_{j}^{\circ}\right)^{k}\right]
$$

will be referred to hereafter as the combined Nearly I deal Multiple Solvent (NIMS)/Redlich-Kister expression. The first summation in eq 5 extends over all solvents (solv) in the multicomponent mixture, whereas the double summation extends over all binary combinations of solvents. In a ternary solvent mixture, as is the case here, there are three binary solvent combinations (BC, BD, and $C D$ ). Equation 4 can be used to predict the solubility as a function of ternary solvent composition, provided that all of the various curve-fit parameters are known. The predictive ability of eq 4 is summarized in Table 3 for anthracene dissolved in the five dibutyl ether + alcohol + cydohexane systems. Examination of the numerical entries in Table 3 reveals that eq 4 predicts the solubility of anthracene to within an overall average absolute deviation of $1.5 \%$, which is comparable to the experimental uncertainty of $\pm 1.5 \%$. For the five systems studied, eq 4 was found to provide very accurate predictions of the observed solubility behavior.

\section{Literature Cited}

Acree, W. E., J r. Mathematical Representation of Thermodynamic Properties. Part 2. Derivation of the Combined Nearly I deal Binary Solvent (NIBS)/Redlich-Kister Mathematical Representation from a Two-Body and Three-Body Interactional Mixing Model. Thermochim. Acta 1992, 198, 71-79.

Acree, W. E., r. Polycyclic Aromatic Hydrocarbons in Pureand Binary Solvents; Volume 54 in IUPAC Solubility Data Series; Oxford University Press: Oxford, U.K., 1994.

Acree, W. E., J. Polycydlic Aromatic Hydrocarbons: Binary Nonaque ous Systems: Part 1 (Solutes A-E); Volume 58 in IUPAC Solubility Data Series; Oxford University Press: Oxford, U.K., 1995a.

Acree, W. E., J r. Polycyclic Aromatic Hydrocarbons: Binary Nonaque ous Systems: Part 2 (Solutes F-Z); Volume 59 in IUPAC Solubility Data Series; Oxford University Press: Oxford, U.K., 1995b.

Acree, W. E., J r.; Zvaigzne, A. I. Thermodynamic Properties of Nonelectrolyte Solutions. Part 4. Estimation and Mathematical Representation of Solute Activity Coefficients and Solubilities in Binary Solvents Using the NIBS and Modified Wilson Equations. Thermochim. Acta 1991, 178, 151-167.

Acree, W. E., J r.; McCargar, J. W.; Zvaigzne, A. I.; Teng, I.-L. Mathematical Representation of Thermodynamic Properties. Carbazole Solubilities in Binary Alkane + Dibutyl Ether and Alkane + Tetrahydropyran Solvent Mixtures. Phys. Chem. Liq. 1991, 23, 27-35.

Acree, W. E., J r.; Zvaigzne, A. I.; Tucker, S. A. Thermochemical Investigations of Hydrogen-Bonded Solutions. Development of a Predictive Equation for the Solubility of Anthracene in Binary Hydrocarbon + Alcohol Mixtures Based U pon Mobile Order Theory. Fluid Phase Equilibr. 1994, 92, 233-253.

Deng, T.; Acree, W. E., J r. Solubility of Anthracene in Ternary Propanol $+2,2,4-$ Trimethylpentane + Cyclohexane and Butanol $+2,2,4$ Trimethyl pentane + Cyclohexane Solvent Mixtures. J . Chem. Eng. Data 1998a, 43, 1059-1061.

Deng, T.; Acree, W. E., J r. Solubility of Anthracene in Ternary Propanol + Butanol + Cyclohexane Solvent Mixtures. J . Chem. Eng. Data 1998b, 43, 1062-1064.

Deng, T.; Childress, S. D.; De Fina, K. M.; Sharp, T. L.; Acree, W. E., $\mathrm{J}$ r. Solubility of Anthracene in Ternary Propanol + Butanol + 2,2,4Trimethyl pentane Solvent Mixtures. J . Chem. Eng. Data 1998, 43, 1065-1067.

Deng, T.; Hernández, C. E.; Roy, L. E.; Acree, W. E., J r. Solubility of Anthracene in Ternary (Propanol + Heptane + Cyclohexane) and (Butanol + Heptane + Cyclohexane) Solvent Mixtures. J. Chem. Thermodyn. 1999a, 31, 205-210.

Deng, T.; Childress, S. D.; De Fina, K. M.; Acree, W. E., J r. Solubility of Anthracene in Ternary Propanol + Butanol + Heptane Solvent Mixtures. Chem. Eng. Commun. 1999b, 172, 217-224.

Marthandan, M. V.; Acree, W. E., J r. Solubility of Anthracene in Binary Solvent Mixtures Containing Dibutyl Ether. J . Chem. Eng. Data 1987, 32, 301-303.

McHale, M. E. R.; Zvaigzne, A. I.; Powell, J . R.; Kauppila, A.-S. M.; Acree, W. E., I r.: Campbell, S. W. Thermochemical Investigations of Hydrogen-Bonded Solutions. Part 9. Comparison of Mobile Order Theory and the Kretschmer-Wiebe Association Model for Predicting Pyrene Solubilities in Binary Alcohol + Alcohol Solvent Mixtures. Phys. Chem. Liq. 1996, 32, 67-87.

Powell, J. R.; Acree, W. E., J r. Solubility of Anthracene in Binary Alcohol + Dibutyl Ether Solvent Mixtures. J . Chem. Eng. Data 1995, 40, 914-916. 
Powell, J . R.; Coym, K. S.; Acree, W. E., J r. Solubility of Anthracene in Binary Alcohol +2 -Methoxyethyl Ether Solvent Mixtures. J. Chem. Eng. Data 1997a, 42, 395-397.

Powell, J. R.; McHale, M. E. R.; Kauppila, A.-S. M.; Acree, W. E., J r.; Flanders, P. H.; Varanasi, V. G.; Campbell, S. W. Prediction of Anthracene Solubility in Alcohol + Alkane Solvent Mixtures Using Binary Alcohol + Alkane VLE Data. Comparison of KretschmerWiebe and Mobile Order Models. Fluid Phase Equilibr. 1997b, 134 185-200.

Zvaigzne, A. I.; Acree, W. E., J r. Solubility of Anthracene in Binary Alkane + 2-Butanol Solvent Mixtures. J. Chem. Eng. Data 1994, 39, 114-116.
Zvaigzne, A. I.; Teng, I.-L.; Martinez, E.; Trejo, J .; Acree, W. E., J r. Solubility of Anthracene in Binary Alkane + 1-Propanol and Alkane + 1-Butanol Solvent Mixtures. J. Chem. Eng. Data 1993, 38, 389392.

Zvaigzne, A. I.; Wolfe, J .; Acree, W. E., J r. Solubility of Anthracene in Binary Alkane + 2-Methyl-1-propanol Solvent Mixtures. J . Chem. Eng. Data 1994, 39, 541-543.

Received for review April 20, 1999. Accepted J une 10, 1999. J E9901076 